\title{
Investigating Anvil Alignment and Anvil Roughness on Flow Pattern Development in High-Pressure Torsion
}

\author{
Yi Huang ${ }^{1}$, Megumi Kawasaki ${ }^{2,3}$, Terence G. Langdon ${ }^{1,2}$ \\ ${ }^{1}$ Materials Research Group, Faculty of Engineering and the Environment, University of Southampton, \\ Southampton SO17 1BJ, U.K. \\ ${ }^{2}$ Departments of Aerospace \& Mechanical Engineering and Materials Science, University of Southern \\ California, Los Angeles, CA 90089-1453, U.S.A. \\ ${ }^{3}$ Division of Materials Science and Engineering, Hanyang University, Seoul 133-791, South Korea
}

\begin{abstract}
High-pressure torsion (HPT) is a processing technique in which samples are subjected to a high pressure and torsional straining. Anvil alignment and anvil roughness are two important factors related to the successful application of the HPT processing technique. Using a two-phase duplex stainless steel as a model material, experiments were conducted by placing the anvils in different amounts of initial misalignment. Experiments show that the flow patterns (the development of double-swirl patterns) in HPT are dependent upon the alignment of the anvils within the HPT facility. Through carefully designed experiments, it is shown that the presence of a double-swirl is a feature of HPT processing when the initial positions of the anvils have a small lateral misalignment. The effect of the double-swirl patterns on the hardness evolution was also evaluated quantitatively. By comparing the flow patterns developed on the disc upper surface using both rough and smooth anvils with a fixed anvil misalignment, it was demonstrated that there are some differences in the flow patterns which are dependent upon the anvil surface roughness.
\end{abstract}

\section{INTRODUCTION}

High-pressure torsion (HPT) is a well-known and widespread processing technique for severe plastic deformation which is capable of producing ultrafine-grained and nanocrystalline metals by imposing high strains on various coarse-grained materials [1-3]. The principles of HPT originated from torsion tests carried out by Bridgman [4] who showed that in a torsion test the fracture strain can be further increased by applying hydrostatic pressure. Thereafter, the method of combining torsion and hydrostatic pressure together to deform materials was developed in the 1980s [5] and is now commonly designated as HPT. There are three different types of HPT facilities termed unconstrained HPT, constrained HPT and quasi-constrained HPT, respectively. In unconstrained HPT, the disc is placed between two flat anvils and the lateral flow of the material is not restricted under the applied pressure. In constrained HPT, the disc is placed within a cavity in the lower anvil so that the lateral flow of the material is totally restricted under the applied pressure. In practice, however, most HPT processing is now conducted under quasi- 
constrained conditions where the disc is contained within shallow depressions on the lower and upper anvils and there is some limited outflow of material between the two anvils [6, 7].

Two important factors that are essential for the torsional straining of disc samples during HPT processing are hydrostatic pressure and micro-roughness of the anvil cavity surface [8]. For torsional straining a minimum pressure is needed in order to obtain sufficient frictional force so that no relative sliding between the anvil and the specimen surface occurs. The maximum applied hydrostatic pressure must be 3 times higher than the yield stress of the processed materials. The second is the anvil cavity area should have a distinctive surface micro-roughness or micro-asperity. These two factors work together to ensure a sufficiently high frictional force which allows the rotational straining of the disc sample.

There are numerous reports on the successful processing of various metallic materials by HPT to obtain ultrafine-grained and nanostructured materials [9-15] but there are very few reports addressing the effect of anvil alignment and anvil roughness on shear deformation and flow pattern development in HPT-processed materials [16-21]. In this report, we describe systematic investigations on the flow pattern development with different anvil alignments and with different anvil roughness.

\section{EXPERIMENTAL MATERIALS AND PROCEDURES}

A commercial F53 super duplex stainless steel was obtained from Castle Metals UK Ltd. in the form of a rolled plate having a thickness of $3 \mathrm{~mm}$. This material was chosen to reveal flow pattern development during HPT because the two phases exhibit good contrast based on earlier results [22-24]. The as-received microstructure consists of a lighter-contrast austenitic $(\gamma)$ and a darker-contrast ferritic $(\alpha)$ phase as shown in Fig.1. The widths of these two phases varied between $\sim 5$ and $\sim 50 \mu \mathrm{m}$.

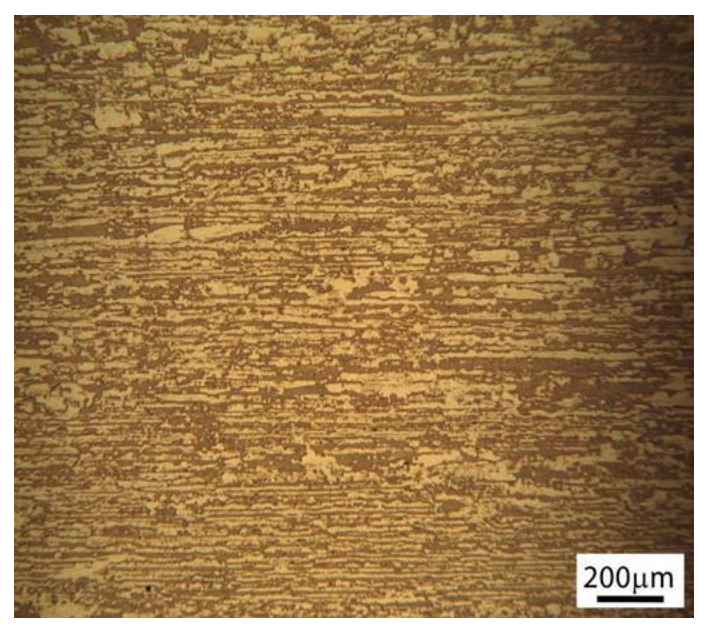

Fig.1 Microstructure of the as-received duplex stainless steel [17]

Processing by HPT was conducted at room temperature under quasi-constrained conditions [6,7]. During HPT processing, the upper anvil is in a fixed position and the lower anvil rotates in a single direction. Any parallel shift between the axis of the upper anvil and the axis of the lower anvil is designated as a measure of the anvil misalignment between the upper 
and lower anvils. Two sets of anvils having different surface roughness (measured by using Alicona Infinite Focus) were used to investigate the flow patterns on the disc top surfaces after HPT. Figure 2 shows the anvil surface profile measurements on the two anvils which are nominally designated as (a) smooth and (b) rough anvils. For each anvil, the upper image is the anvil surface morphology as represented by a set of unique colours shown by the colour key on the right, and the lower image is the result of surface roughness measurements along the anvil surface shown in the upper image. The measured average surface roughness values are a smooth anvil with $\mathrm{Ra}=5 \mu \mathrm{m}$ and a rough anvil with $\mathrm{Ra}=15 \mu \mathrm{m}$.

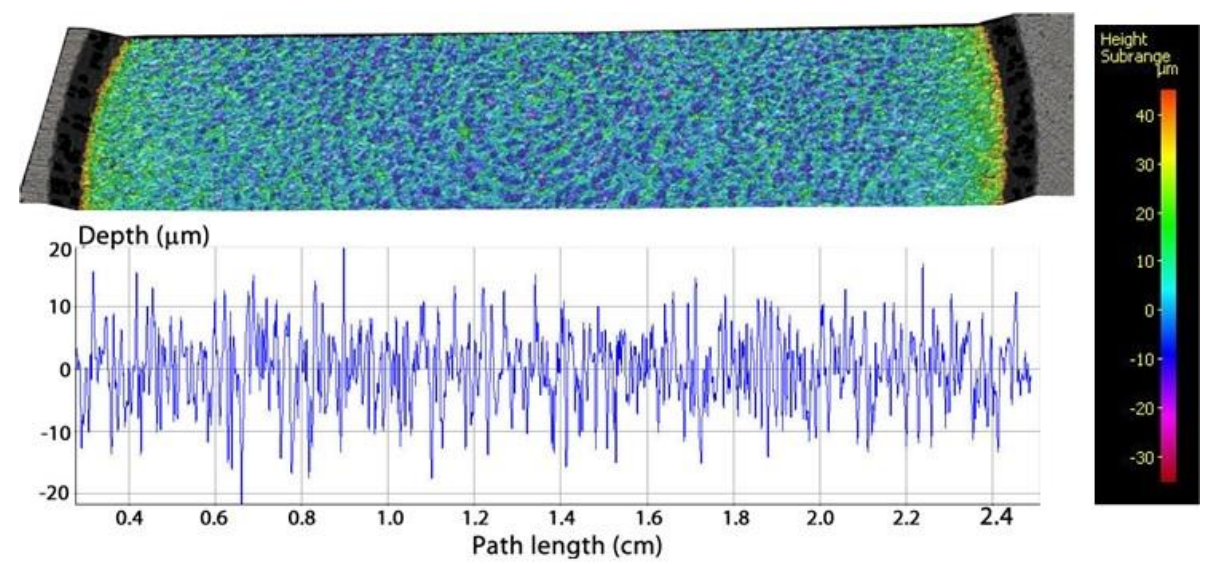

(a)

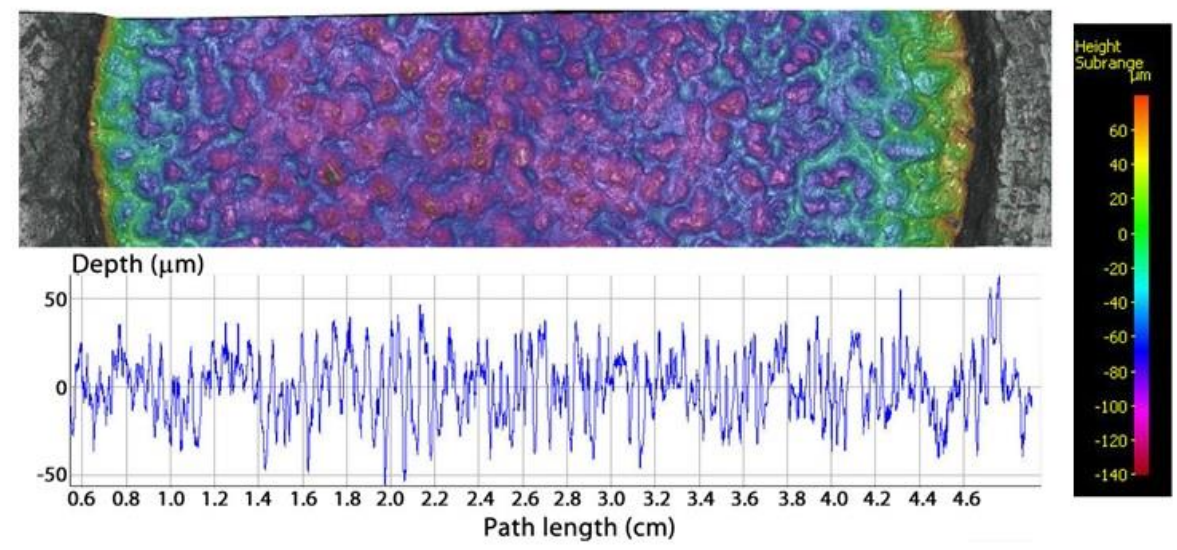

(b)

Fig. 2 Anvil surface profile measurements on (a) the smooth anvil and (b) the rough anvil [20,21]

The present experiments were conducted by making changes in the anvil alignment prior to HPT processing with smooth anvils; then by fixing the anvil alignment to $100 \mu \mathrm{m}$ to process materials using smooth anvils and rough anvils. Three different conditions of anvil alignment were utilised in these experiments: (1) A standard alignment with a parallel shift smaller than 25 $\mu \mathrm{m}$; (2) A misalignment of about $100 \mu \mathrm{m}$ with a deliberate parallel shifting of the upper anvil; (3) A misalignment of about $200 \mu \mathrm{m}$ again with a deliberate parallel shifting of the upper anvil.

HPT was conducted using an applied pressure of $6.0 \mathrm{GPa}$ and a rotation speed of $1 \mathrm{rpm}$ through total numbers, $\mathrm{N}$, of 1 and 5 turns. After HPT processing, samples were electro-etched 
using an electrolyte of $40 \% \mathrm{NaOH}$ solution at $25^{\circ} \mathrm{C}$ to reveal the local microstructures using an Olympus BH optical microscope.

The hardness measurements were taken using an FM300 hardness tester with a load of $300 \mathrm{gf}$ and a dwell time of $15 \mathrm{~s}$. For samples processed with a standard anvil alignment $(<25 \mu \mathrm{m})$ and anvil misalignments of 100 and $200 \mu \mathrm{m}$ using smooth anvils, the values of the Vickers microhardness, Hv, were evaluated by mapping the values of $\mathrm{Hv}$ over the total surface of each individual disc following a rectilinear grid pattern with separations of $0.3 \mathrm{~mm}$ between each consecutive point and then using these datum points to construct color-coded contour maps to provide a visual display of the hardness variations across the surface of each disc. A detailed description of the procedure was reported earlier [25]. For samples processed with a fixed anvil misalignment of $100 \mu \mathrm{m}$ using smooth and rough anvils, the hardness was measured at positions along the disc diameters separated by incremental distances of $0.3 \mathrm{~mm}$.

\section{EXPERIMENTAL RESULTS}

\section{Flow patterns and hardness development by HPT with different anvil alignments}

Smooth anvil, standard alignment $(<25 \mu \mathrm{m}), \mathrm{N}=1$, top surface

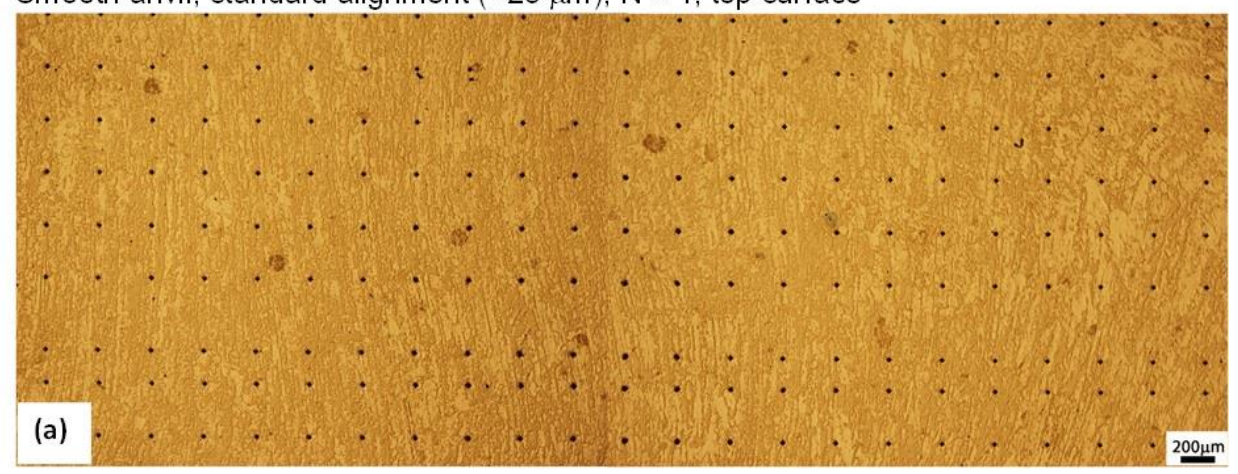

Smooth anvil, standard alignment $(<25 \mu \mathrm{m}), \mathrm{N}=5$, top surface

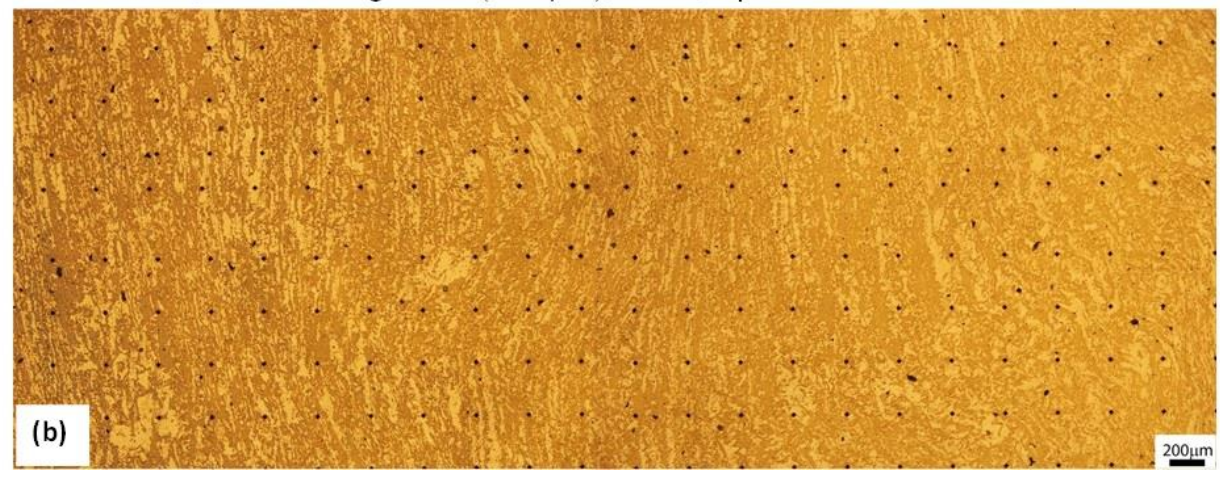

Fig. 3 The flow pattern development under a standard alignment $(<25 \mu \mathrm{m})$ for (a) $\mathrm{N}=1$ turn and (b) $\mathrm{N}=5$ turns [18] 
Figures 3-5 are consolidated images of the disc top surfaces along the diameters, showing microstructure features and flow pattern development with the standard anvil alignment $(<25 \mu \mathrm{m})$ and misalignment of $100 \mu \mathrm{m}$ and $200 \mu \mathrm{m}$ during HPT processing with smooth anvils. The rows of black dots in the images correspond to the marks from hardness mapping indentations.

With the standard anvil alignment $(<25 \mu \mathrm{m})$ as shown in Fig. 3, both discs exhibited similar flow patterns with the phase domains remaining reasonably straight in the centres of the discs after 1 turn and 5 turns processing. Comparing with the straight phase domains in the asreceived materials shown in Fig.1, it appears that the use of a standard anvil alignment produces flow patterns that are reasonably consistent with the conventional rigid-body analysis [26].

The appearances of the surfaces after processing using an anvil misalignment of $100 \mu \mathrm{m}$ are shown in Fig. 4 for the discs processed through 1 and 5 turns. These images clearly display the curvatures of the phase domains. Furthermore, close inspection shows there are pairs of curvatures for both conditions and these pairs correspond to double-swirls with each swirl having a unique swirl centre. It is apparent that the double-swirl configurations tend to decrease in size with increasing numbers of turns.
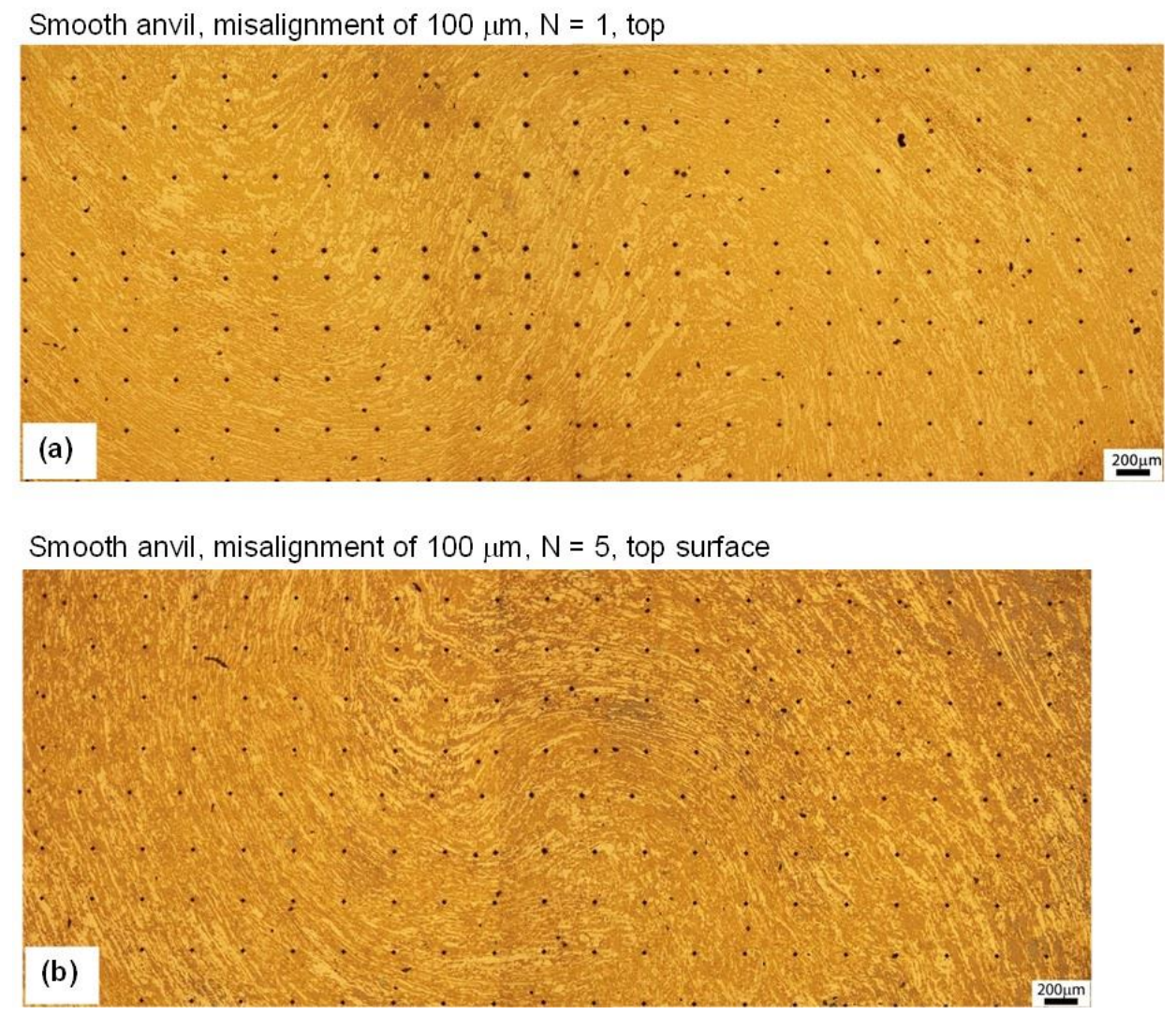

Fig. 4 The flow pattern developments under an anvil misalignment of $100 \mu \mathrm{m}$ for (a) $\mathrm{N}=1$ turn and (b) $\mathrm{N}=5$ turns $[18,20]$

The results of surface flow pattern development for an anvil misalignment of $200 \mu \mathrm{m}$ are shown in Fig. 5. Double-swirl flow patterns are visible in both discs processed to 1 turn and 5 turns. Comparing with Fig. 4, it is apparent that there is a similar pattern as with the anvil 
misalignment of $100 \mu \mathrm{m}$, so that the double-swirl configuration tends to decrease in size with increasing numbers of turns. The distances between the two centres of the double-swirls decrease with the increasing torsional straining.
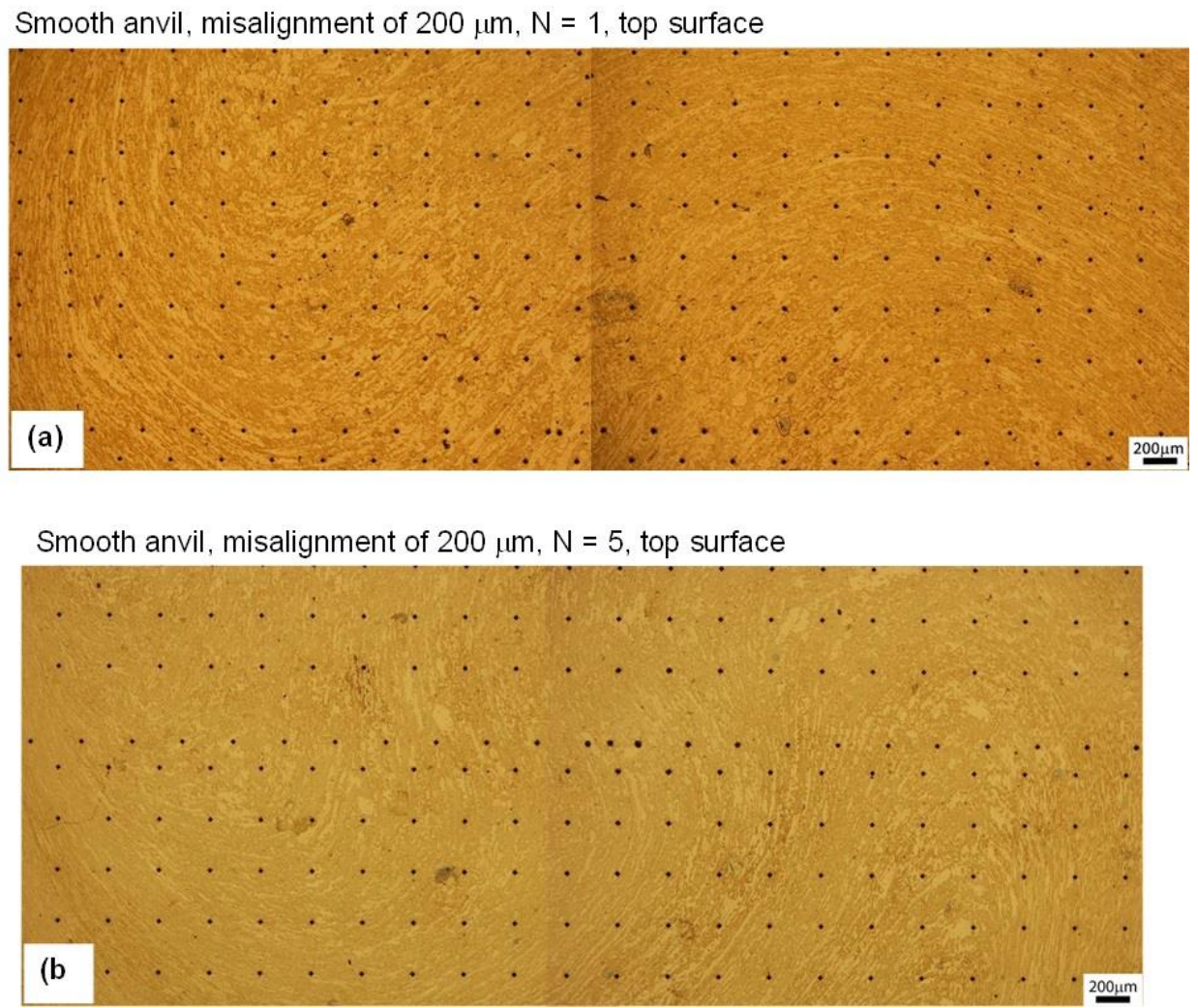

Fig. 5 The flow pattern developments under an anvil misalignment of $200 \mu \mathrm{m}$ for (a) $\mathrm{N}=1$ turn and (b) $\mathrm{N}=5$ turns [18]

In order to have an overall visual evaluation of the hardness distributions throughout the surfaces of the discs after processing with different anvil alignments, the hardness values for all discs are displayed pictorially as colour-coded contour maps in Fig. 6. Three alignment conditions (the standard alignment and misalignments of $100 \mu \mathrm{m}$ and $200 \mu \mathrm{m}$ ) with $\mathrm{N}=1$ turn and $\mathrm{N}=5$ turns are in turn presented in Fig. 6. In these plots, the coordinate system $\mathrm{X}$ and $\mathrm{Y}$ denotes two randomly selected perpendicular axes that are superimposed on the discs such that the central point in every disc is given by the coordinates $(0,0)$ and the individual values of $\mathrm{Hv}$ are represented by a set of unique colours denoting values from 350 to 650 in incremental steps of 50 as shown by the colour key on the right of Fig. 6 .

The results in Fig. 6 show that the areas of lower hardness in the disc centre region decrease from 1 to 5 turns for all three alignment conditions. By careful inspection of the $\mathrm{N}=1$ turn samples, it is found that the region of lower hardness is slightly smaller in the disc with standard alignment than in discs with anvil misalignments of $100 \mu \mathrm{m}$ and $200 \mu \mathrm{m}$; also the disc edge area has higher hardness value with anvil misalignment $200 \mu \mathrm{m}$ than discs with standard alignment $(<25 \mu \mathrm{m})$ and anvil misalignment of $100 \mu \mathrm{m}$. For $\mathrm{N}=5$ turns samples, the disc centre has a larger low hardness area with $200 \mu \mathrm{m}$ anvil misalignment than discs with standard 
alignment $(<25 \mu \mathrm{m})$ and anvil misalignment of $100 \mu \mathrm{m}$, but there is not much hardness difference in the disc edge area for the three alignment conditions. The larger regions of lower hardness recorded in the discs with a misalignment of $200 \mu \mathrm{m}$ indicate there is a slower microstructural evolution towards homogeneity when discs are processed with a misalignment of $200 \mu \mathrm{m}$. In addition, the centres of minimum hardness are displaced from the centres for discs with misalignments of 100 and $200 \mu \mathrm{m}$, and especially with a misalignment of $100 \mu \mathrm{m}$.

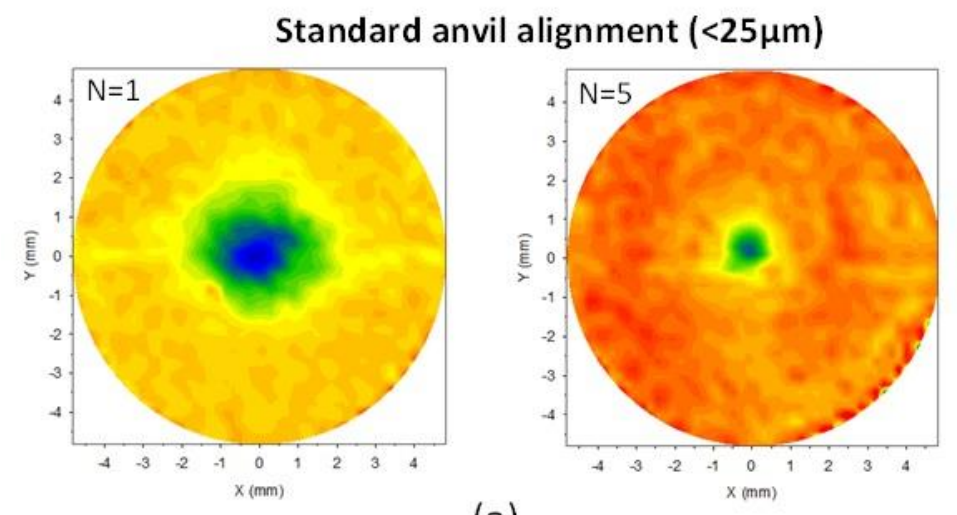

(a)

Anvil misalignment of $100 \mu \mathrm{m}$
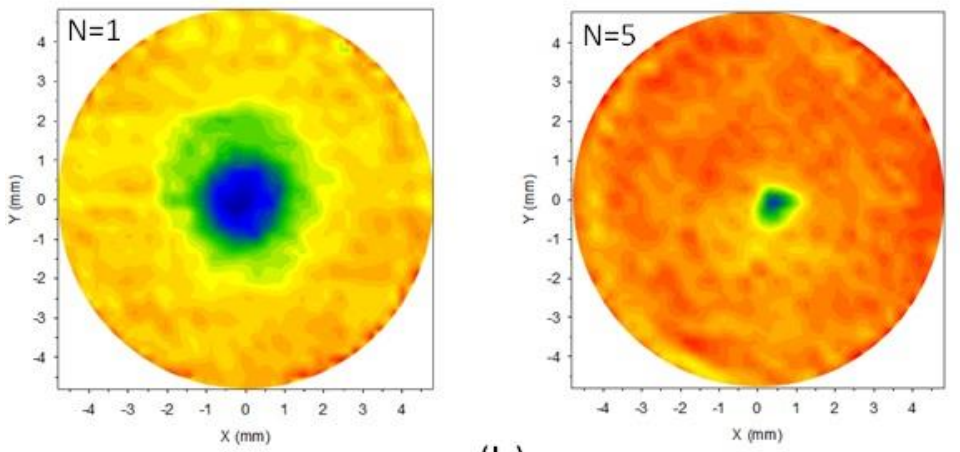

(b)

Anvil misalignment of $200 \mu \mathrm{m}$
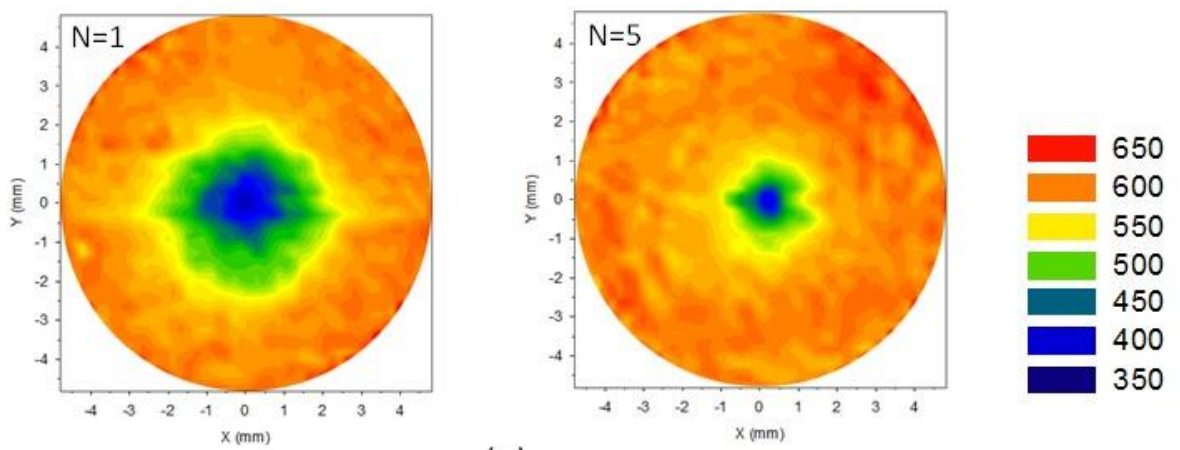

(c)

Fig. 6 Colour-coded maps of the Vickers microhardness distributions over disc surfaces with (a) a standard alignment (<25 $\mu \mathrm{m})$ and misalignments of (b) $100 \mu \mathrm{m}$ and (c) $200 \mu \mathrm{m}$ [18] 


\section{Flow patterns and hardness development by HPT with different anvil roughness}

Fig. 4 shows the flow pattern developed on the disc top surface with $100 \mu \mathrm{m}$ of anvil misalignment when using smooth anvils. The appearance of the disc top surface shows clearly defined curvature of the phase domain and overall double-swirl flow patterns for both 1 turn and 5 turns samples. With fixed $100 \mu \mathrm{m}$ of anvil misalignment, when using rough anvils for HPT processing the flow patterns on the disc top surface are displayed in Fig. 7.

Rough anvil, misalignment of $100 \mu \mathrm{m}, \mathrm{N}=1$, top surface

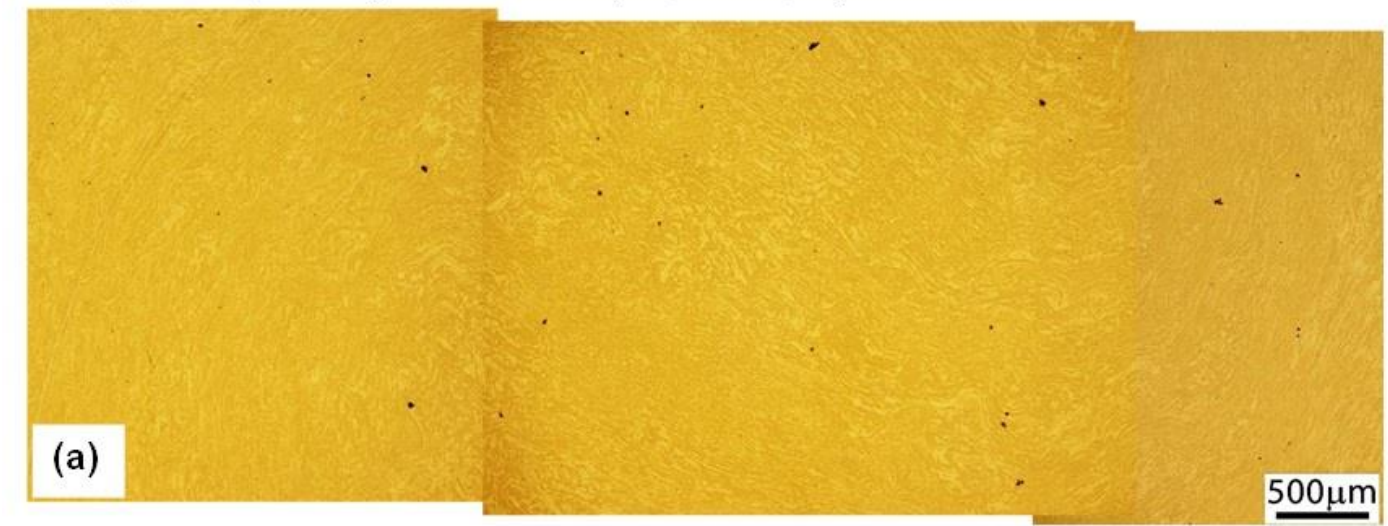

Rough anvil, misalignment of $100 \mu \mathrm{m}, \mathrm{N}=5$, top surface

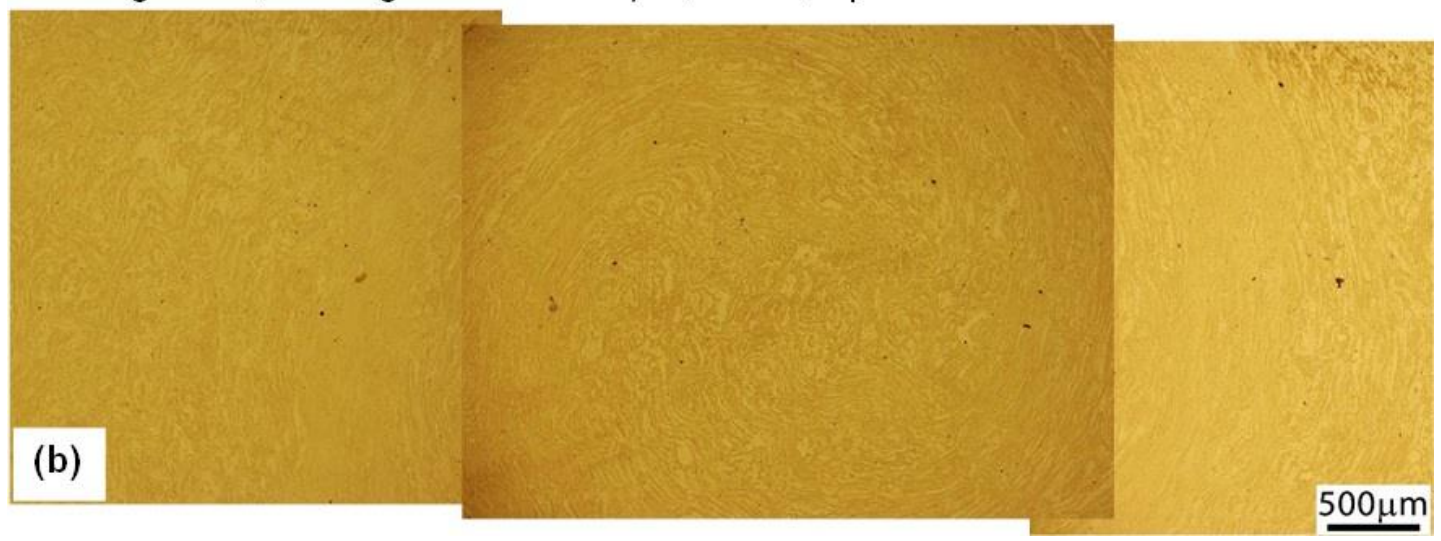

Fig. 7 The flow pattern development on the disc top surface while using rough anvils ( $\mathrm{Ra}=15$ $\mu \mathrm{m}$ ) with an anvil misalignment of $100 \mu \mathrm{m}$ for (a) $\mathrm{N}=1$ turn and (b) $\mathrm{N}=5$ turns [20]

A double-swirl flow pattern can be recognized on the disc top surface after 1 turn in Fig. 7a but the double-swirl is not clearly-defined as on the top surface when using smooth anvils in Fig. 4a. A comparison of Fig. 4a with Fig. 7a shows that the austenitic $(\gamma)$ and the ferritic $(\alpha)$ phases are clearly distinguished and the curvature of the phase domains is smooth when using smooth anvils whereas the overall curvature of the phase domains is not smooth so that some areas show clear two phase contrast and other areas display unclear phase contrast when using rough anvils. An earlier report confirms that unclear phase contrast area is a significant area of 
the phase domain with thinned widths of austenitic $(\gamma)$ and ferritic $(\alpha)$ phase [20]. These observations suggest that local deformation, such as local variations in widths of the austenitic $(\gamma)$ and ferritic $(\alpha)$ phase refinement, lead to a non-uniform appearance for the phase domains.

After 5 turns, the disc top surface shows an overall single swirl appearance in Fig. 7b. There appears to be a clear phase contrast and some unclear phase contrast area. An earlier report confirmed the unclear phase contrast area is the area where the widths of the austenitic $(\gamma)$ and the ferritic $(\alpha)$ phases are significantly refined [20]. Again, these observations confirm the occurrence of non-uniform deformation on the disc top surface.

To compare the influence of smooth and rough anvils on the mechanical characteristics of the top surfaces, the hardness distributions were recorded after 1 and 5 turns as presented in Fig. 8 for (a) 1 turn and (b) 5 turns.

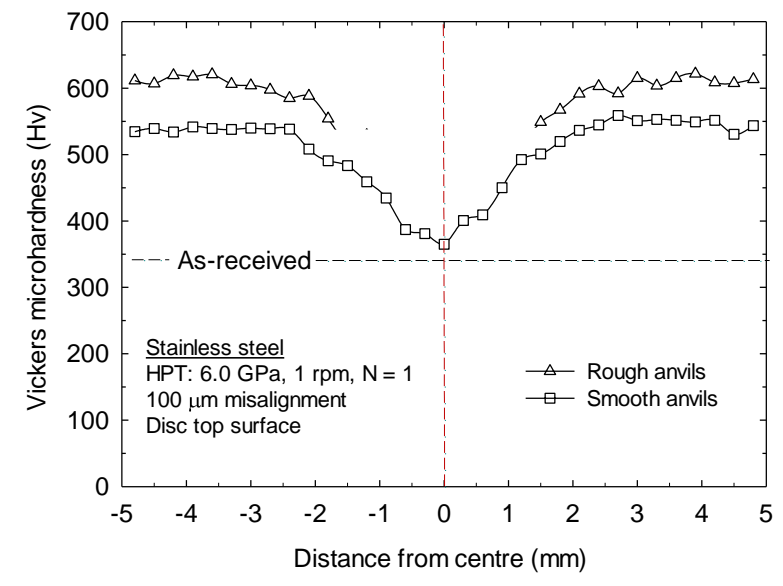

(a)

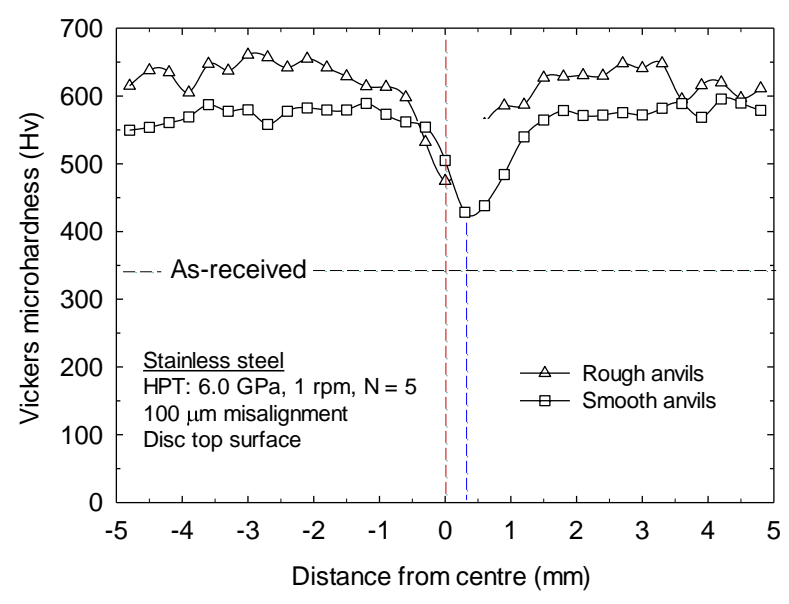

(b)

Fig. 8 Hardness distributions on the disc top surface after (a) $\mathrm{N}=1$ turn and (b) $\mathrm{N}=5$ turns using smooth and rough anvils [20]

After 1 turn, the use of smooth anvils introduces double-swirl flow patterns on the disc top surface whereas rough anvils lead to the appearance of double-swirls with non-uniform phase domain contrast. As shown in Fig. 8a, the hardness values on the top surface using the rough anvil are larger than with the smooth anvil. Nevertheless, the hardness distributions from the smooth and rough anvils display similar variations across the discs with a minimum hardness in the centre, higher values towards the edges and with evidence for a saturation condition at the edge of the disc over an outer ring having a width of about $2 \mathrm{~mm}$.

After 5 turns, the smooth anvil generates double-swirl flow patterns on the top surface whereas the rough anvil produces the appearance of a single swirl with a non-uniform phase domain contrast in the swirl area. In Fig. 8b the microhardness values after 5 turns are again larger for the rough anvil. Furthermore, after 5 turns the position of the minimum hardness is displaced from the disc centre for the smooth anvil but it remains essentially in the centre position for the rough anvil. 


\section{DISCUSSION}

\section{The origin of the double-swirl flow patterns with different anvil alignment}

When using smooth anvils with different anvil alignments (standard alignment, anvil misalignments of $100 \mu \mathrm{m}$ and $200 \mu \mathrm{m}$ ), Figs. 3-5 reveal significant differences in flow pattern development. Fig. 3 shows no double-swirls are visible on the top surfaces of discs processed to 1 turn and 5 turns using a standard anvil alignment $(<25 \mu \mathrm{m})$ which corresponds to a normal operating condition for HPT processing, whereas double-swirls are recorded on discs processed with anvil misalignments of $100 \mu \mathrm{m}$ and $200 \mu \mathrm{m}$ as displayed in Figs. 4-5. Also, the doubleswirl pattern tends to become smaller as straining is continued to larger numbers of turns.

The absence of any double-swirls in the discs processed with a good initial anvil alignment confirms that these unusual flow patterns are not an inherent feature of processing by HPT. On the contrary, the presence of a double-swirl is a feature of HPT processing when the initial positions of the anvils have a small lateral misalignment. Thus, the results from this investigation serve to clarify both the origin and the nature of the double-swirl flow pattern developed during HPT processing.

Fig. 6 shows that the hardness values of the discs tend to be consistent across all of the discs for all alignment conditions, thereby demonstrating there are no obvious differences between the hardness distributions in the curved phase domains of the double-swirls and the areas outside of these curved phases.

\section{Effect of anvil roughness on flow patterns and hardness development}

Comparing the surface morphology images of the depressions within the smooth and rough anvils in Fig. 2, it is apparent that the smooth anvil has not only a smaller value of Ra but also a smaller area for each pit. Overall, the smooth anvil surface in Fig. 2a has shallow pits and a reasonably uniform pit distribution whereas the rough anvil surface in Fig. $2 b$ has deeper and larger pits with a fairly non-uniform distribution. With the rough anvil, the pit area and pit depth are large and the pit distribution is non-uniform so that the local frictional forces change from place to place during the HPT processing. These variations in the local frictional forces would affect the flow patterns of the deformed materials. With the smooth anvil, the pit area and pit depth are relatively small and the pit distribution is reasonably uniform so that the local frictional force is reasonably uniform from place to place during the HPT processing. Due to the different surface roughness characteristics of the smooth and rough anvils, it is apparent that samples processed to the same numbers of rotations will have different flow patterns and hardness distributions depending on the precise nature of the anvil surfaces.

After 1 turn of rotation, there are clear double-swirl flow patterns on the disc top surface of a sample processed with the smooth anvil (Fig. 4a) whereas the double-swirls are less easy to identify (i.e. can be defined as recognizable double-swirl flow pattern to distinguish with clear double-swirl flow pattern) on the sample processed using the rough anvil (Fig. 7a). After 5 turns of rotation, there are clear double-swirl flow patterns on the disc top surface when using the smooth anvil (Fig. 4b) whereas there is a single swirl flow pattern on the sample processed using the rough anvil (Fig. 7b). It is reasonable to assume that variations in the local frictional forces 
introduced by the rough anvil contribute to the so-called recognisable double-swirl flow patterns after 1 turn and single-swirl flow patterns after 5 turns.

Both the flow patterns and the refinement in width of the austenitic $(\gamma)$ and the ferritic $(\alpha)$ phases make contributions to the hardness distributions on the top surfaces of the discs. Using rough anvils, whether disc top surfaces display recognizable double-swirl flow pattern after 1 turn or single swirl flow pattern after 5 turns, the common feature for 1 turn and 5 turns samples is that there exists many local significantly refined austenitic $\gamma$ and ferritic $\alpha$ phases with unclear phase domains. This lead to higher hardness values in the samples processed to 1 turn and 5 turns when using the rough anvil compared to when using smooth anvils (Fig. 8).

\section{SUMMARY}

1) Double-swirl flow patterns develop on the disc top surfaces when using a smooth anvil with anvil misalignment of 100 and $200 \mu \mathrm{m}$ but there are no double-swirls when processing with standard alignment $(<25 \mu \mathrm{m})$.

2) When using a rough anvil, the disc top surfaces have single swirl flow patterns for 5 turns whereas for 1 turn the disc top surface has a recognisable double-swirl flow pattern.

3) While using rough anvils, there are non-uniform phase domains with some areas having significantly refined austenitic $\gamma$ and ferritic $\alpha$ phases. These features are attributed to variations in the local frictional forces which cause unstable flow and non-uniform structural refinement.

4) Due to the local refinement of the austenitic $\gamma$ and ferritic $\alpha$ phases when using the rough anvil, the disc top surface has larger hardness values than when using a smooth anvil.

\section{ACKNOWLEDGEMENTS}

This work was supported by the European Research Council under ERC Grant Agreement No. 267464-SPDMETALS.

\section{REFERENCES}

[1] R.Z. Valiev, R.K. Islamgaliev and I.V. Alexandrov, Prog. Mater. Sci. 45, 103-189 (2000).

[2] A.P. Zhilyaev and T.G. Langdon, Prog. Mater. Sci. 53, 893-979 (2008).

[3] T.G. Langdon, Acta Mater. 61, $7035-7059$ (2013).

[4] P.W. Bridgman, J. Appl. Physics 14, 273-283 (1943).

[5] N.A. Smirnova, V.I. Levit, V.I. Pilyugin, R.I. Kuznetsov, L.S. Davydova and V.A. Saznova, Fiz Metal Metalloved 61(6), 1170-1177(1986).

[6] R.B. Figueiredo, P.R. Cetlin and T.G. Langdon, Mater Sci Eng. A 528, 8198-8204 (2011).

[7] R.B. Figueiredo, P.H.R. Pereira, M.T.P. Aguilar, P.R. Cetlin and T.G. Langdon, Acta Mater. 60, 3190-3198 (2012).

[8] A. Hohenwarter, A. Bachmaier, B. Gludovatz, S. Scheriau and R. Pippan, International J. Mater. Res. 100, 1653-1661 (2009). 
[9] C. Xu, Z. Horita and T.G. Langdon, Acta Mater. 55, 203-212 (2007).

[10] J. Wongsa-Ngam, M. Kawasaki, Y. Zhao and T.G. Langdon, Mater. Sci. Eng. A 528, 77157722 (2011).

[11] K. Edalati, A. Yamamoto, Z. Horita and T. Ishihara, Scripta Mater. 64, 880-883 (2011).

[12] M. Kawasaki, R.B. Figueiredo and T.G. Langdon, Acta Mater. 59, 308-316 (2011).

[13] A. Loucif, R.B. Figueiredo, T. Baudin, F. Brisset, R. Chemam and T.G. Langdon, Mater. Sci. Eng. A 532, 139-145 (2012).

[14] J. Wongsa-Ngam, M. Kawasaki and T.G. Langdon, J. Mater. Sci. 47, 7782-7788 (2012).

[15] S. Sabbaghianrad, M. Kawasaki and T.G. Langdon, J. Mater. Sci. 47, 7789-7795 (2012).

[16] Y. Huang, M. Kawasaki and T.G. Langdon, Adv. Eng. Mater. 15, 747-755 (2013).

[17] Y. Huang, M. Kawasaki and T.G. Langdon, J. Mater. Sci. 48, 4533-4542 (2013).

[18] Y. Huang, M. Kawasaki and T.G. Langdon, J. Mater. Sci. 49, 3146-3157 (2014).

[19] Y. Huang, M. Kawasaki and T.G. Langdon, Mater. Sci. Forum 783-786, 45-50 (2014).

[20] Y. Huang, M. Kawasaki, A. Al-Zubaydi and T.G. Langdon, J. Mater. Sci. 49, 6517-6528 (2014).

[21] Y. Huang, A. Al-Zubaydi, M. Kawasaki and T.G. Langdon, J. Mater. Res. Tech. 3, 303310 (2014).

[22] Y. Cao, Y.B. Wang, S.N. Alhajeri, X.Z. Liao, W.L. Zheng, S.P. Ringer, T.G. Langdon and Y.T. Zhu, J. Mater. Sci. 45, 765-770 (2010).

[23] Y. Cao, M. Kawasaki, Y.B. Wang, S.N. Alhajeri, X.Z. Liao, W.L. Zheng, S.P. Ringer, Y.T. Zhu and T.G. Langdon, J. Mater. Sci. 45, 4545-4553 (2010).

[24] Y. Cao, Y.B. Wang, R.B. Figueiredo, L. Chang, X.Z. Liao, M. Kawasaki, W.L. Zheng, S.P. Ringer, T.G. Langdon and Y.T. Zhu, Acta Mater. 59, 3903-3914 (2011).

[25] M. Kawasaki and T.G. Langdon, Mater. Sci. Eng. A 498, 341-348 (2008).

[26] R.Z. Valiev, Yu.V. Ivanisenko, E.F. Rauch and B. Baudelet, Acta Mater. 44, 4705-4712 (1996). 